\title{
Gut microbiota of homologous Chinese soft-shell turtles (Pelodiscus sinensis) in different habitats
}

\author{
Benli Wu', Long Huang ${ }^{1}$, Jing Chen ${ }^{1}$, Ye Zhang ${ }^{1}$, Jun Wang ${ }^{2}$ and Jixiang $\mathrm{He}^{\mathrm{1}^{*}}$
}

\begin{abstract}
Background: Chinese soft-shell turtle (Pelodiscus sinensis) is an important commercial species for their high nutritional value and unique taste, but it has been a vulnerable species due to habitat loss. In this study, homologous juvenile turtles were allocated to lake, pond and paddy field to investigate the habitat effects on turtles.
\end{abstract}

Results: The growth, morphology and gut microbial communities were monitored during the 4 months cultural period. It showed higher growth rate of turtles in paddy field and pond. The appearance, visceral coefficients, gut morphology and microbial communities in turtles were distinct among different habitats. The microbial community richness on Chao1 was obviously lower in initial turtle guts from greenhouses, whereas it was relative higher in turtle guts sampled from paddy fields than ponds and lake. Significant differences on dominant microbes were found among initial and subsequent samples from different habitats. Firmicutes was the most abundant phylum in the guts of turtles sampled from the greenhouse initially, while Proteobacteria was the most abundant phylum after cultivation in different habitats, followed by Bacteroidetes. The microbial composition were distinct in different habitats at 60d, and the appearance of dominant phyla and genera was more driven by sampling time than habitats at $120 \mathrm{~d}$. Both the sampling time and habitats affected the appearance of dominant phyla and genera during the cultivation. The functional predictions indicated that both habitat type and sampling time had significant effects on metabolic pathways, especially amino acid and carbohydrate metabolism.

Conclusions: The turtles could adapt to natural lakes, artificial ponds and paddy fields. The gut microbial abundance was different among the habitats and sampling time. The species of microbes were significantly more diverse in paddy field specimens than in those from ponds and lakes. Rice-turtle coculture is a potential ecological and economic farming mode that plays important roles in wild turtle protection and food security.

Keywords: Gut microbial variation, Diversity, Habitat, Rice-turtle coculture.

\footnotetext{
* Correspondence: hejixiangah@sina.com

'Key Laboratory of Aquaculture \& Stock Enhancement of Anhui Province, Fisheries Research Institute, Anhui Academy of Agricultural Sciences, No.40 Nongkenan Road, Luyang District, Hefei 230031, Anhui Province, China Full list of author information is available at the end of the article
} 


\section{Background}

Owing to their high nutritional value and unique taste, the consumption of wild animals is popular in many countries and areas, which has accelerated the recession of wild resources. However, some of the wild animals that are consumed may carry highly pathogenic viruses and bacteria that pose a potential threat to humans. Moreover, wildlife conservation has become an impending issue in recent decades. Chinese soft-shell turtle (Pelodiscus sinensis, hereinafter referred to as turtle) is an important commercial aquatic species in Southeast Asia, including China, and is commonly considered a tonic food due to its high nutritive and medicinal value $[1,2] . P$. sinensis has become a vulnerable species due to habitat loss and overfishing [3]. These turtles live in water and have been traditionally cultured in lakes, rivers or reservoirs at low stocking densities. Currently, several modes of captive culture have been promoted to satisfy market demand; greenhouses and artificial ponds are commonly selected as sites for high production turtle aquaculture [4]. Intensive cultivation can significantly increase the production of commercial turtles while shortening the culture period; however, it is also accompanied by problems such as a high risk of disease, defective appearance and low quality. Furthermore, the high energy consumption of these rearing patterns is not conducive to sustainable agricultural development and has aroused increasing public concern $[4,5]$. Intensive breeding can cause diseases such as bacterial infection and mesenteritis in aquaculture species due to the associated crowded living spaces and superfluous but simple food sources [6-8]. Consequently, antiseptic medicines and antibiotics have been abused leading the rise in antibiotic resistance $[9,10]$, thus leading to more serious environmental and health problems that affect both the quality of the product and animal welfare [1113]. Probiotics have been developed for both cultured animals and humans as immunopotentiators [14, 15], but their positive effects are limited and temporary; thus, more healthy culture modes should be applied for high-quality aquatic products $[16,17]$.

Turtles from different habitats generally show obvious differences in appearance, morphology, textural properties, chemical composition and flavor substance contents $[5,18]$. Physiological disorders are associated with marked changes in gut microbial communities. The gut microbiota is a protective barrier of organisms to prevent pathogen invasion and is affected by both the internal and external environment for mammals as humans and mouses [19-21]. The diversity and variation of gut microbial communities have been considered indicators of the health status of cultured fishes [22]. In recent years, the coculture of rice and aquatic animals, such as rice-fish, rice-crayfish and rice-turtle systems, has been rapidly developed in Southeast Asian regions, especially in South
China [23]. Paddy fields can provide capacious space, shelter and natural food for cultured animals. Cultured animals prey on pests, and the activities of the cultured animals could loosen the soil and provide organic fertilizer for paddies, thus significantly decreasing the utilization of chemical fertilizers and pesticides [24, 25]. Therefore, the coculture mode has been considered an economic and ecological culture mode in rice-growing regions.

Host genetics, diets and ambient environmental conditions could affect the composition of the complex gut microbiota in fish $[26,27]$. But it is difficult to fully unravel the diversity and dynamics of gut microbiota and identify keystone species for specific functions [16]. In the present study, homologous juvenile turtles with similar genotypes and early life conditions were allocated to different habitats to investigate their differences in growth and morphology and analyze the diversity and variation in their gut microbial communities within cultural periods. Efforts were also made to identify functional microbes or representative communities as biomarkers of the physiological status of turtles in different habitats.

\section{Results}

Turtle growth and morphology under different habitats Mortality was negligible in both paddy fields and ponds during the experimental period. However, only a small number of turtles were caught from the lake at $60 \mathrm{~d}$, and no marked turtles were recaptured at $120 \mathrm{~d}$, resulting in incomplete statistics for mortality and growth for turtles in the lake. No wild turtles were caught during sampling. A relatively small sample size $(n=3)$ for each group was designed for turtle resource protection purposes, and it was difficult to sample from natural lakes. There were significant differences in growth among the different groups; the body weights of turtles in paddy fields and ponds were obviously higher than those in lakes $(p<0.05)$, and divergence occurred in the early days. The growth rates of turtles were $0.76 \% / d, 0.68 \% / d$ and $0.40 \% / \mathrm{d}$ for those from paddy fields, ponds and lakes, respectively, in the first $60 \mathrm{~d}$. The rate was $0.72 \% /$ $\mathrm{d}$ and $0.62 \% / \mathrm{d}$ for turtles from paddy fields and ponds, respectively, during the whole $120 \mathrm{~d}$. The hepatosomatic index and clumpy fat index were highest in ponds, second in paddy fields and lowest in lakes $(p<$ 0.05). The gut-somatic index of weight $\left(\mathrm{DSI}_{\mathrm{W}}\right)$ for turtles from ponds was significantly higher than that for turtles from lakes and paddy fields $(p<0.05)$. Conversely, the gut-somatic index of length $\left(\mathrm{DSI}_{\mathrm{L}}\right)$ was higher for turtles from paddy fields and lakes than those from ponds. Measured values are presented as the mean \pm standard deviation, and the different superscript letters in the same row indicate significant differences $(p<0.05)$ (Table 1). 
Table 1 The anatomical indices of turtles from different habitats and cultured days

\begin{tabular}{|c|c|c|c|c|c|c|c|c|}
\hline \multirow[t]{2}{*}{ Indices } & \multicolumn{3}{|l|}{ Od } & \multicolumn{3}{|l|}{$60 d$} & \multicolumn{2}{|l|}{$120 \mathrm{~d}$} \\
\hline & Field & Pond & Lake & Field & Pond & Lake & Field & Pond \\
\hline BW & $335.8 \pm 22.2$ & $341.3 \pm 32.6$ & $344.9 \pm 26.8$ & $529.7 \pm 35.5^{b}$ & $512.2 \pm 39.3^{b}$ & $438.8 \pm 27.4^{a}$ & $796.6 \pm 58.2^{b}$ & $717.2 \pm 64.6^{a}$ \\
\hline $\mathrm{CL}$ & $12.89 \pm 0.09$ & $12.91 \pm 0.06$ & $12.92 \pm 0.07$ & $15.96 \pm 0.26^{b}$ & $15.87 \pm 0.30^{b}$ & $15.30 \pm 0.28^{a}$ & $17.71 \pm 0.35^{b}$ & $17.13 \pm 0.38^{a}$ \\
\hline $\mathrm{CW} / \mathrm{CL}$ & $0.909 \pm 0.006$ & $0.914 \pm 0.002$ & $0.914 \pm 0.003$ & $0.768 \pm 0.006^{\mathrm{a}}$ & $0.766 \pm 0.08^{a}$ & $0.779 \pm 0.005^{b}$ & $0.782 \pm 0.010$ & $0.786 \pm 0.008$ \\
\hline $\mathrm{CLW} / \mathrm{CL}$ & $0.150 \pm 0.002$ & $0.149 \pm 0.002$ & $0.149 \pm 0.002$ & $0.164 \pm 0.006^{a}$ & $0.178 \pm 0.005^{b}$ & $0.174 \pm 0.008^{b}$ & $0.203 \pm 0.06^{a}$ & $0.217 \pm 0.010^{b}$ \\
\hline SGR & - & - & - & 0.76 & 0.68 & 0.40 & 0.72 & 0.62 \\
\hline HSI & $2.9 \pm 0.2$ & $2.9 \pm 0.2$ & $2.9 \pm 0.2$ & $3.0 \pm 0.3^{b}$ & $3.1 \pm 0.2^{b}$ & $2.8 \pm 0.3^{a}$ & $2.6 \pm 0.2^{a}$ & $2.7 \pm 0.2^{b}$ \\
\hline FSI & $3.8 \pm 0.2$ & $3.8 \pm 0.2$ & $3.8 \pm 0.2$ & $3.6 \pm 0.2^{b}$ & $4.2 \pm 0.2^{c}$ & $2.9 \pm 0.2^{\mathrm{a}}$ & $3.6 \pm 0.1^{a}$ & $3.9 \pm 0.2^{b}$ \\
\hline GSIW & $2.6 \pm 0.1$ & $2.6 \pm 0.1$ & $2.6 \pm 0.1$ & $2.1 \pm 0.1^{\mathrm{a}}$ & $2.3 \pm 0.1^{b}$ & $2.1 \pm 0.1^{a}$ & $2.1 \pm 0.0^{\mathrm{a}}$ & $2.4 \pm 0.1^{b}$ \\
\hline$G S I_{\llcorner}$ & $4.0 \pm 0.2$ & $4.0 \pm 0.2$ & $4.0 \pm 0.2$ & $4.0 \pm 0.1$ & $3.9 \pm 0.1$ & $4.0 \pm 0.1$ & $3.7 \pm 0.2^{b}$ & $3.5 \pm 0.2^{a}$ \\
\hline
\end{tabular}

BW (g): body weight

$\mathrm{CL}(\mathrm{cm})$ : carapace length

$\mathrm{CW}(\mathrm{cm})$ : carapace width

CLW (cm): calipash lateral width

SGR (Specific Growth Rate, $\left.\% / d): 100 \times\left(\operatorname{Ln}_{\left(B W_{T}\right)}\right)-\operatorname{Ln}\left(B W_{0}\right)\right) / T$

HSI (Hepatosmatic Index,\%) $=100 \times$ liver weight $/$ BW

FSI (Clumpy Fat Index,\%) = 100xclumpy fat weight/ BW

$\mathrm{GSI}_{\mathrm{w}}$ (Gut-smatic Index on Weight,\%) =100xgut weight/BW

$\mathrm{GSI}_{\mathrm{L}}$ (Gut-smatic Index on Length) = gut length $/$ Carapace length

There was no obvious trauma experienced by most turtles from the lake except occasional parasitic leeches observed on the calipash. However, more bruises or scars were observed for the turtles from ponds than those from paddy fields. The appearance, such as the color, of the carapace and plastron were different among turtles from different habitats. The carapace of turtles cultured in ponds presented a bottle green color, but the individuals from paddy fields presented a bottle green color with a slight golden yellow color, which was similar to turtles from lakes. There were significant differences in carapace width/carapace length $(\mathrm{CW} / \mathrm{CL})$ and calipash lateral width/carapace length $(\mathrm{CLW} / \mathrm{CL})$ values at $60 \mathrm{~d}$ and $120 \mathrm{~d}(p<0.05)$, and the $C W / C L$ value was relatively higher for turtles from lakes, and CLW/CL was higher for turtles from lakes and ponds than for those from paddy fields $(p<0.05)$ (Table 1$)$.

\section{Composition and diversity of turtle gut microbiota}

The grouping details for samples from different habitats, culture days and intestinal segments are listed in Table 2 . For gut samples, a total of 1723158 valid bacterial $16 \mathrm{~S}$ rRNA gene reads were obtained, and 4901 OTUs were identified from all samples. The observed total OTUs varied from $64 \sim 822$. The total number of OTUs was significantly lower in initial groups IF and IL and higher in groups F1F and F1L from paddy fields at $60 \mathrm{~d}$. The number of OTUs was $17 \sim 48$, representing more than

Table 2 Grouping details for samples from different habitats, cultured days and intestinal segment

\begin{tabular}{|c|c|c|c|c|}
\hline Groups & Body weight(g) & Living habitats & Cultured days & Sampled gut segment \\
\hline IF & $340.5 \pm 6.7$ & Greenhouse & Od (I) & Foregut (F) \\
\hline IL & & Greenhouse & Od (I) & Hindgut (L) \\
\hline F1F & $530.3 \pm 5.6$ & Paddy Field(F) & $60 d(1)$ & Foregut (F) \\
\hline F1L & & Paddy Field(F) & $60 d(1)$ & Hindgut (L) \\
\hline $\mathrm{F} 2 \mathrm{~F}$ & $806.6 \pm 10.2$ & Paddy Field(F) & $120 d(2)$ & Foregut (F) \\
\hline $\mathrm{F} 2 \mathrm{~L}$ & & Paddy Field(F) & $120 d(2)$ & Hindgut (L) \\
\hline P1F & $515.0 \pm 7.3$ & Artificial Pond(P) & $60 d(1)$ & Foregut (F) \\
\hline P1L & & Artificial Pond(P) & $60 d(1)$ & Hindgut (L) \\
\hline P2F & $720.4 \pm 3.3$ & Artificial Pond(P) & $120 d(2)$ & Foregut (F) \\
\hline $\mathrm{P} 2 \mathrm{~L}$ & & Artificial Pond(P) & $120 d(2)$ & Hindgut (L) \\
\hline L1F & $350.3 \pm 5.1$ & Natural Lake(P) & $60 d(1)$ & Foregut (F) \\
\hline L1L & & Natural Lake(P) & $60 d(1)$ & Hindgut $(L)$ \\
\hline
\end{tabular}

The letters or numbers in groups names indicated "Habitat", "Sampling time"and "Gut segment", respectively, which were also shown in the parentheses. Body weight here was average body weight of the three sampled turtles for each groups 
$0.01 \%$ of the total OTUs (Table S1). Significant differences were found in OTU composition among groups (Fig. S1). Guts sampled at $120 \mathrm{~d}$ had few unique OTUs, both in the foregut and hindgut. Rarefied OTUs (with reads normalized to 35,000 for each sample) was adopted to do diversity and richness analysis. We picked Chaol and Shannon as richness and evenness indicator, respectively. The index of Chao1 was higher in the hindgut than those in the foregut at 60d, whereas it was higher in turtle guts sampled from paddy fields than ponds and lakes. In addition, the Chao1 index was significantly lower in initial turtle guts from greenhouse compared to the samples from the three different habitats $(p<0.05)$ (Fig. 1a). The shannon index was relative higher in foregut than hindgut samples, whereas it was also relative higher in foregut samples from paddy field than pond and lake at $60 \mathrm{~d}$ (Fig. 1b). The species and number of OTUs varied significantly at $60 \mathrm{~d}$, different from the relatively similar results across groups obtained at $120 \mathrm{~d}$. The microbial abundance was higher in samples from paddy fields than in samples from lakes and ponds during the experiment. The microbial community presented relatively high similarity in guts sampled at the same time. The PCoA (principal coordinate analysis) of the Bray-Curtis dissimilarity showed high microbial community similarity in guts from the same individual or group and significant discrepancy in samples from different habitats, sampling times and gut sections (Fig. 2, Fig. S2). Generally, both sampling time and habitat affected the variation in the gut microbial communities.

\section{Dominant microbes}

The recognized microbes belonged to 27 phyla, 59 classes, 97 orders, 151 families, and 219 genera from all the samples based on GreenGene. The phylum and genus levels were emphasized in the analysis. Bacteroidetes, Firmicutes, Fusobacteria and Proteobacteria were the most dominant phyla, accounting for more than $95 \%$ of the total bacteria in all samples. Firmicutes was the most abundant phylum in the guts of turtles sampled from the greenhouse initially, while Proteobacteria was the most abundant phylum after cultivation in different
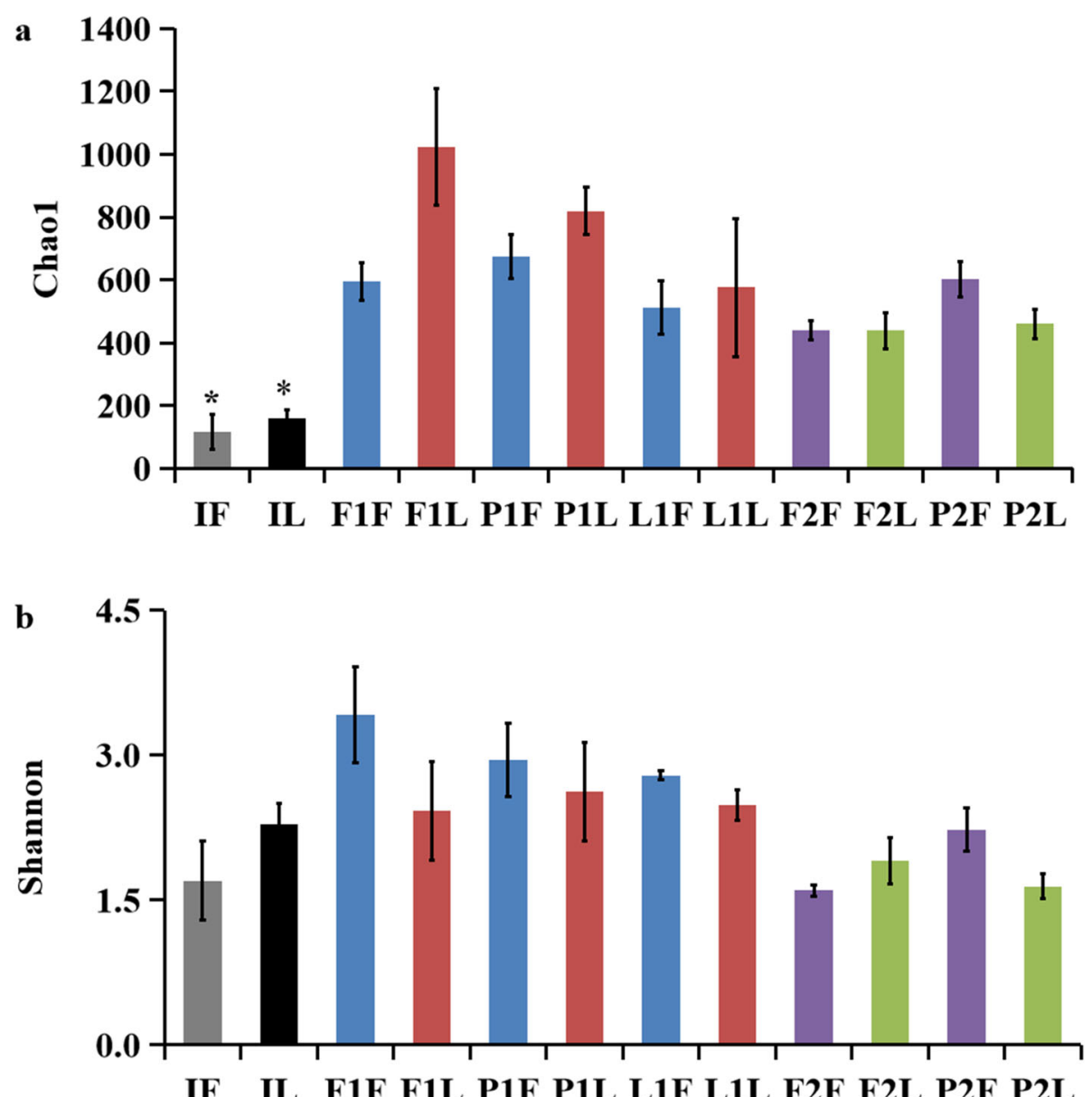

Fig. 1 Richness (Chao1, a) and evenness (Shannon, b) indices of gastrointestinal microbial communities on OTUs, the *on the bar indicated significant differences with other groups, the grouping details were listed in Table 2 


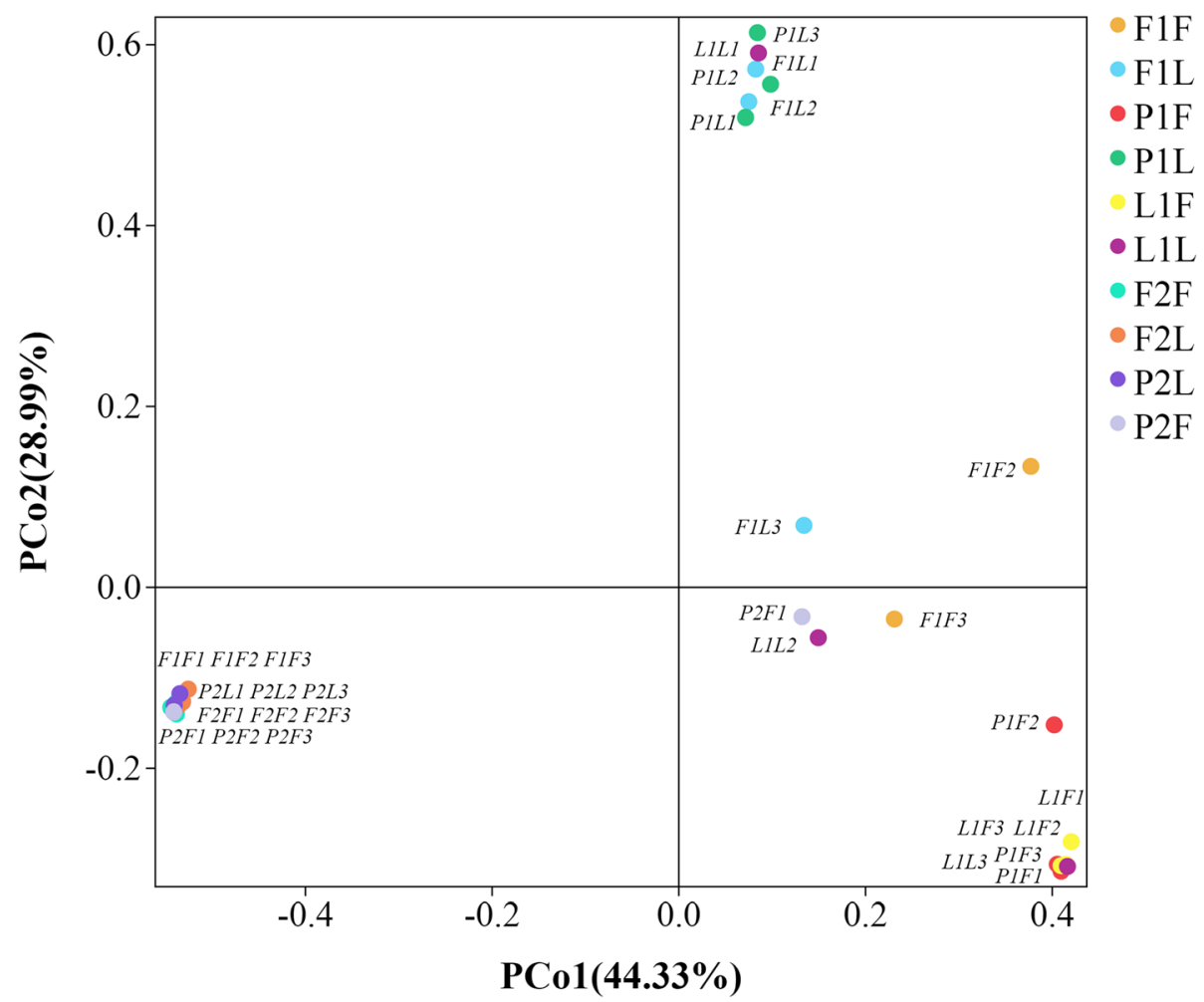

Fig. 2 The PCOA (principal co-ordinates analysis) on Bray-Curtis, the different symbols represented different groups from different habitats and cultural periods, the grouping details were listed in Table 2

habitats, followed by Bacteroidetes. Firmicutes and Fusobacteria commonly existed at $60 \mathrm{~d}$ but were rarely present at $120 \mathrm{~d}$ in turtles from all three habitats (Fig. 3a). Additionally, the unidentified bacteria were more abundant in turtles from lakes than those from paddy fields and ponds.

There was a significant difference in dominant genera among initial samples and subsequent samples from different habitats. The dominant genera in the initial samples were an unclassified genus belonging to Bacteroidales, Romboutsia, Cetobacterium, Weissella, Lactococcus, Lactobacillus, Clostridium, Edwardsiella, Plesiomonas, and Sarcina. For samples from the three habitats mentioned above, the dominant genera were Cetobacterium, Chryseobacterium, Clostridium, Epulopiscium, Flavobacterium, Helicobacter, Pseudomonas, Stenotrophomonas and another unclassified genus belonging to Xanthomonadaceae. The abundance of dominant genera varied with habitat, sampling time and gut location. For turtles sampled from paddy fields, the most dominant genus in foregut samples taken at $60 \mathrm{~d}$ was Clostridium, and in the hindgut, it was Cetobacterium, while at $120 \mathrm{~d}$, the most dominant genus was Stenotrophomonas both in the foregut and hindgut. For turtles sampled from ponds, the most dominant genera at $60 \mathrm{~d}$ were Flavobacterium and Cetobacterium in the foregut and hindgut, while at $120 \mathrm{~d}$, the most dominant genus was also Stenotrophomonas. For turtles sampled from the lake, the most dominant genera at $60 \mathrm{~d}$ were Flavobacterium and Cetobacterium in the foregut and hindgut, respectively (Fig. 3b).

The dominant species in different gut locations were also distinct. In the foregut, the dominant species were Weissella cibaria, Enterococcus durans, Lactobacillus sakei, Lactococcus lactis, Lactococcus garvieae, Sarcina $s p$. and Pseudomonas sp., whereas in the hindgut, Clostridium sensu stricto, Romboutsia sp., Weissella cibaria, Escherichia coli, Plesiomonas shigelloides, Edwardsiella tarda, Paeniclostridium sp., Cetobacterium sp., Terrisporobacter $s p$. and two other unclassified species belonging to Bacteroidales were the most abundant.

\section{Microbial communities in turtles from different habitats and at different sampling times}

The microbial community was relatively complex at $60 \mathrm{~d}$, especially in the foregut. At $60 \mathrm{~d}$, the species of microbes were significantly more abundant in turtles from the fields, followed by those from ponds and lakes. There were 140 common species $(8.2 \%)$ in the foreguts of turtles from the three different habitats (Fig. 4a); Flavobacterium sp., Pseudomonas sp., Chryseobacterium sp. and two species belonging to Xanthomonadaceae were relatively abundant. 

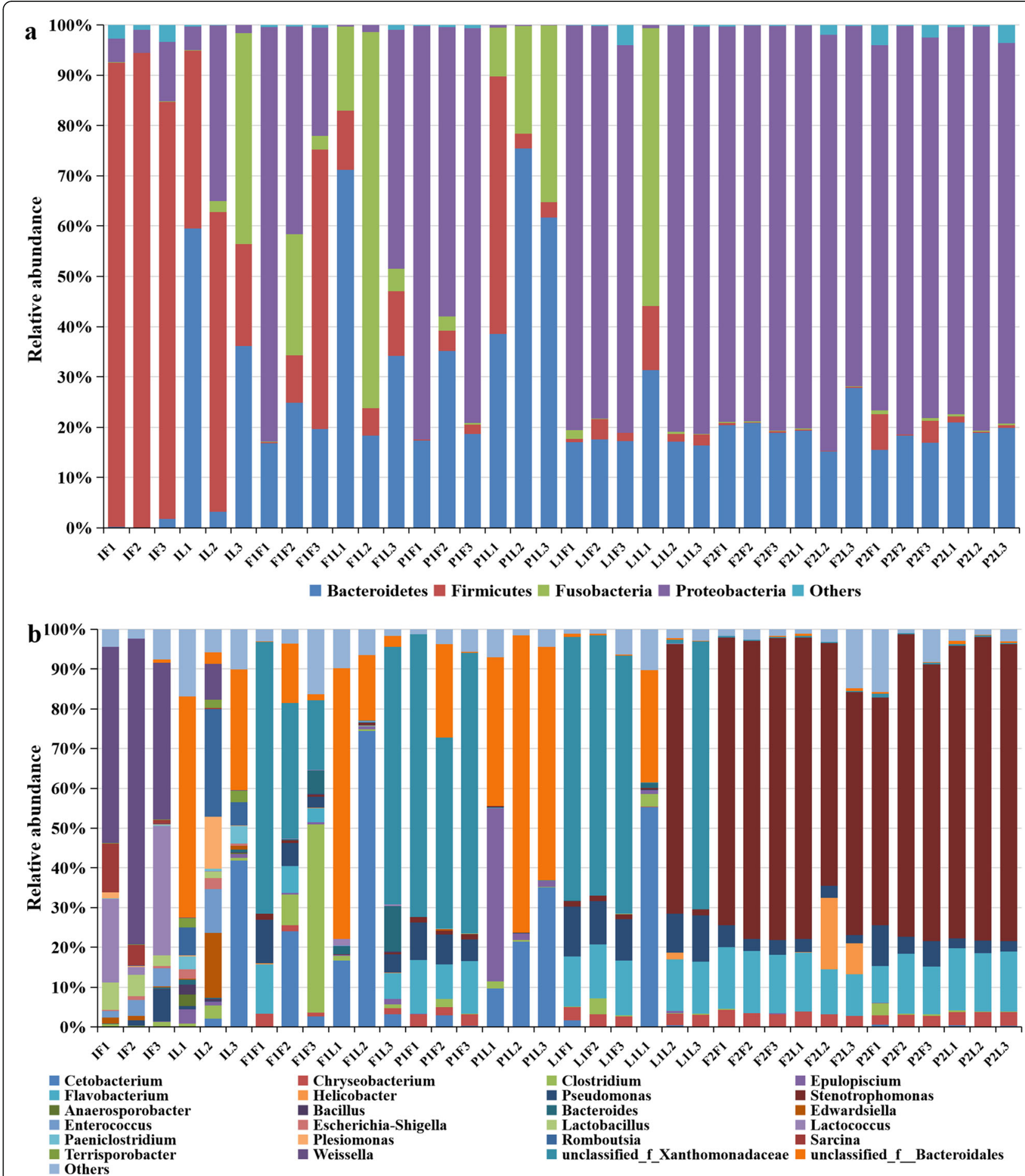

Fig. 3 The dominant phyla (a) and genera (b) of gut microbial community under different habitats and sampling time, the grouping details were listed in Table 2 and the last number $(1,2,3)$ in group label indicated sample number

Cetobacterium somerae was more abundant in turtles from paddy fields than in those from ponds and lakes. For the hindgut, there were 205 common species $(8.1 \%)$ in turtles from the three different habitats (Fig. 4b). Among these, one species belonging to
Bacteroidaceae was abundant in all habitats. Cetobacterium somerae, Epulopiscium sp., Pseudomonas sp., Stenotrophomonas sp. and Flavobacterium sp. were more abundant in turtles from paddy fields and lakes than in ponds, while Clostridium sp. and Epulopiscium sp. were 

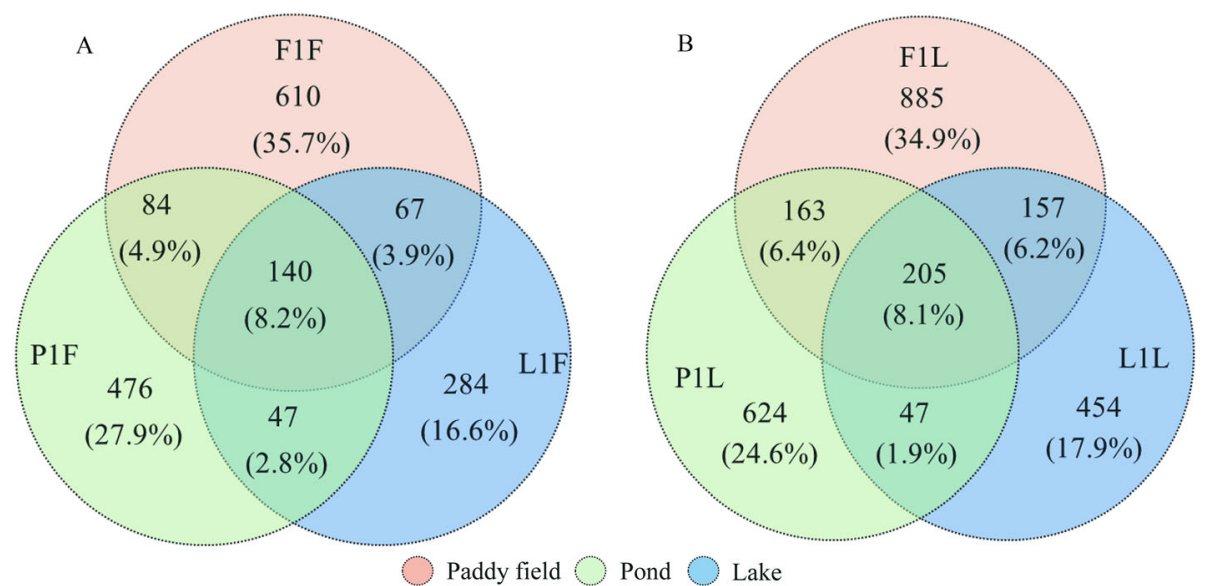

Fig. 4 The Venn chart on gut microbial species for three different habitats at 60d, different circles represented different habitats, the percentage indicated number of species/total species in the three habitats, the grouping details were listed in Table 2

relatively abundant in specimens from ponds. Moreover, Chryseobacterium sp., Parabacteroides sp., Sphingobacterium faecium, Clostridium perfringens, Pseudomonas sp., Bacteroides sp. and Pseudomonas sp. commonly existed in samples from lakes and paddy fields but did not appear in pond samples. At $120 \mathrm{~d}$, specific foregut microbes were more abundant in pond turtles $(74 \%)$ than paddy field turtles $(33.4 \%)$, and the common species accounted for $18.6 \%$; for the hindgut, specific microbes were more abundant in paddy field turtles $(44 \%)$ than pond turtles (34.4\%), and the common species accounted for $26.1 \%$ (Fig. S3).

LEfSe analysis was also conducted to identify representative microbes among various groups. For the initial groups, representative genera were Weissella, Cetobacterium, Chryseobacterium, Epulopiscium, Escherichia, Flavobacterium, Lactococcus, Leuconostoc, Plesiomonas, Romboutsia, Sarcina and Stenotrophomonas. For groups cultured in different habitats, F1L contained more different species than the other groups, including members of Cetobacterium, Lactobacillaceae, Bacteroides, Parabacteroides, Plesiomonas, and several species belonging to the phylum Firmicutes presented higher LDA scores than those of the other groups. For F1F, the representative taxa were Sutterella, Bacteroides and Clostridiales. For samples from the lake, Xanthomonadaceae and Pseudomonadales were representative taxa, especially at $60 \mathrm{~d}$. The representative microbes in pond turtles were numerous and belonged to various phyla, especially the phylum Proteobacteria, and some unassigned species were found turtles from this habitat (Fig. 5).

\section{Functional predictions}

The nearest sequenced taxon index (NSTI) was developed to quantify the availability of nearby genome representatives for groups (Table S2). In total, 39 predicted functional categories that represented 7 pathway maps in level 2 were indicated by PICRUSt, including 275 functions on level 3. Culture period and habitats had significant effects on metabolism such as amino acid and carbohydrate metabolism, environmental and genetic information processing such as membrane transport, replication and repair, especially at $60 \mathrm{~d}$ (Fig. S4). At $60 \mathrm{~d}$, the functional microbiota in foregut related to amino acid and carbohydrate metabolism was distinct higher in paddy field samples compared to those from ponds and lake, while in hindgut, the functional microbiota were more abundant in pond samples than lake and paddy field (Fig. 6, Fig. S4).

\section{Discussion}

Turtles had the same general microbiota regardless of origin, body size and habitat and presented fast adaptation after allocation to different habitats [28]. The differentiation of growth, behavior and physiology of the homologous turtles appeared under different living habitats in a short period. Environmental changes can substantially influence the intestinal microbiome of mammalian and aquatic animals $[29,30]$. The differences might be attributed to living space[6], water quality, food composition and abundance [31, 32], and prey and predation conditions for different habitats [33]. Considering the similarity of natural conditions, such as geographical location, climate, rainfall and temperature, among the mentioned three habitats, the food intake and relative living space might be the main factors determining the growth and physiology of turtles in this study, referring to the researches of aquaic animals as perch (Perca fluviatilis), crucian carp (Carassius auratus) and African cichlid fishes [34-36]. Wild turtles are predominantly carnivorous and prey on small fish, mollusks, crustaceans, insects or their larvae, and 


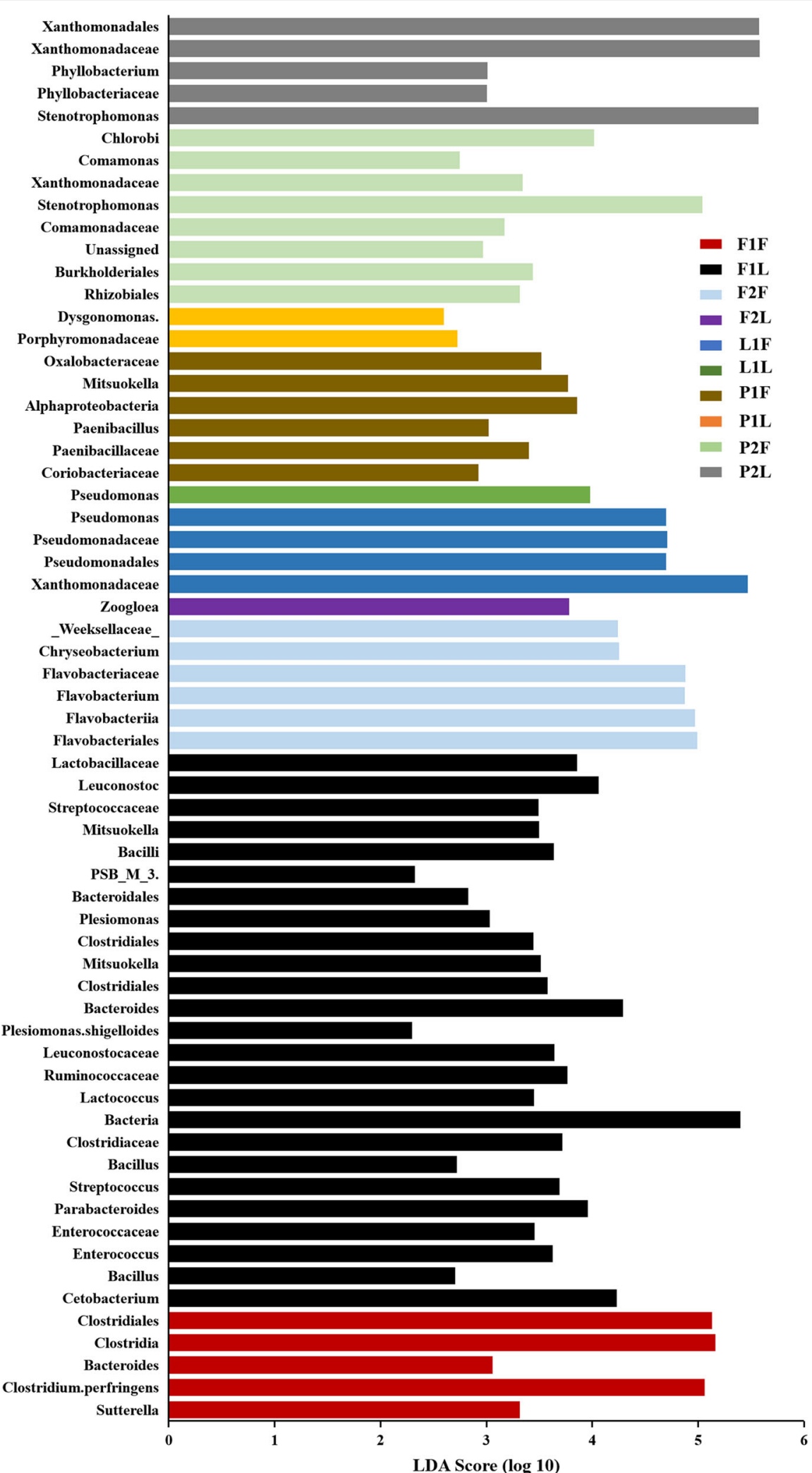

Fig. 5 The species with significant differences in abundance for different groups and their effects, the LDA Scores $(\geq 2)$ were listed and the higher score means bigger effects, the grouping details were listed in Table 2 


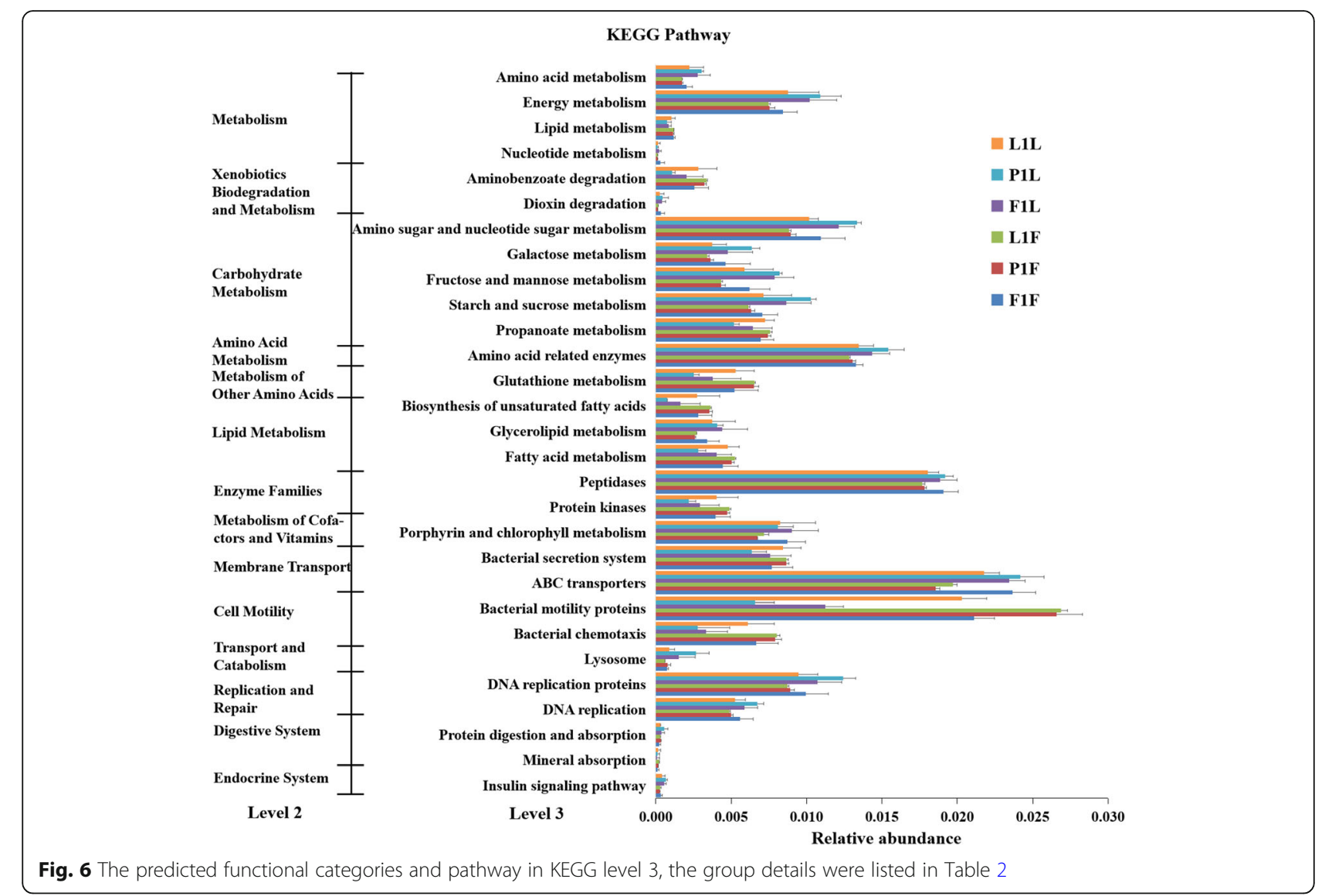

occasionally some plant seeds, but food abundance is affected by the aquatic environment, competitors and natural enemies in different habitats $[37,38]$. In the present study, turtles in paddy fields and ponds were regularly fed artificial feeds, but no such feeds were provided for turtles in the lake during the experiment. In addition, gastropods and insect larvae commonly exist as supplementary food in lakes and paddy fields but rarely exist in ponds [39]. The stocking density in lakes was undoubtedly lower than that in paddy fields and ponds, and the lake environment was relatively stable with capacious water and less disturbance. However, more competitors, predators and parasites existed in the lake, but negligible interspecific competition occurs in this habitat [40]. The paddy field in this study was a complicated habitat with environmental features such as common fields and ponds. The paddy field provided spacious living space, and rice plants served as shelter for turtles. The high growth rate of turtles in this habitat might be attributed to the relatively low stocking density and sufficient food in paddy fields. He et al. (2017) demonstrated that the taste of turtles cultured in paddy fields was better than that of turtles in cultured ponds based on the texture and chewiness of the meat, which might also be due to the broad space of paddy fields for turtle activities [18].
All of these results indicated that the extensive living space of paddy fields could promote growth and quality with proper amounts of food.

Food and feeding strategies obviously affected the morphology and function of the digestive system [41], and a previous study on perch demonstrated that the relative gut length was shorter under stress conditions such as food shortage [34]. For cultured fishes as gilthead sea bream (Sparus aurata) and rare minnow (Gobiocypris rarus), sufficient feeds might enhance digestive function and promote the development of the gut at an earlier feeding stage, but continuous regular feeding with sufficient food might decrease appetite and digestive activities, along with changes in gut morphology and structure $[42,43]$. The gut presented obvious adaptation to habitat, and the relative length of the gut was significantly lower in ponds than in paddy fields and lakes. This might be related to the complicated food composition in lakes and paddy fields, and increased nutrient absorption and prolonged intestinal transit time for turtle [44], which was also found in gibel carp (Carassius auratus gibelio) [45]. Although the turtles in ponds were apparently fed to satiation during the experiment, the fixed and simple artificial feed might not be compatible with the ingestion habits of the turtles, and 
the food species or types also influenced the internal environment and gut microbial communities [46].

The gut microbiota was closely associated with host physiological metabolism, nutrient utilization, nutritional status, immunity, and even health for aquatic animals $[47,48]$. The microbes originally derived from previous generations of experimental animals as mouse and human beings in previous studies played important roles in the formation of gut microbial communities and microecological systems [21, 49]. The habitats would also affect the gut microbiota and there were significant differences in gut microbial composition under different habitats for zebrafish (Danio rerio), mice and Antarctic seals in previous studies [50, 51]. In general, the microbial population is less diverse in diseased organisms than in healthy organisms. The gut microbial species were more abundant in paddy fields and ponds than in lakes at $60 \mathrm{~d}$, while the species were fewer, and no obvious differences were found among the three habitats at $120 \mathrm{~d}$. This might be due to an obvious reduction in feed intake at $120 \mathrm{~d}$. The dominant phyla and genera were relative similar regardless of the habitats at $120 \mathrm{~d}$, and the appearance of dominant phyla and genera was more driven by sampling time than habitats. But the microbial composition were distinct in different habitats at $60 \mathrm{~d}$, and both the sampling time and habitats affected the appearance of dominant phyla and genera during the cultivation (Fig. 3). The study on threespine stickleback (Gasterosteus aculeatus) showed the composition and abundance of gut microbial communities varied under different habitats to adapt to habitat heterogeneity [52]. In previous studies on zebrafish and dogs, food was deemed as a main factor that influenced gut morphology, homeostasis and microbiota, providing nutrients for the body and acting as a fermentation substrate for gut microbes [53, 54]. The microbial gut communities varied greatly when the Atlantic salmon (Salmo salar) were fed diets of different compositions [55]. Therefore, the gut microbita of turtles would be also affected by food supply in various habitats.

Ambient water conditions such as temperature and dietary changes affect the microbiome composition in Atlantic salmon [56,57], and a suitable diet is conducive to improve the intestinal environment and increase the abundance of probiotics [48]. The PICRUSt functional predictions revealed that both the cultural periods (different seasons) and habitats had significant effects on metabolism, especially amino acid and carbohydrate metabolism, which also indicated the key role of food intake on the gut microbial community in mouse [58]. Moreover, the gut microbiota further influences the metabolic activity of the host as African turquoise killifish (Nothobranchius furzeri) [59].
Most previous studies on fish, poultry and mammals have focused on factors that affect the gut microbial community, such as genotype, rearing conditions and diet [60-62]. However, the causality between the microbial community and specific diseases is ambiguous, such as obesity in rodents and humans [63, 64]. Healthy individuals often have intricate and stable gut microbial communities, and pathogenic bacteria might disturb homeostasis and microbial balance, which may manifest as a reduction in gut microbial species and richness. In contrast, in recent studies on grass carp (Ctenopharynodon idellus), more bacteria and higher alpha diversity were observed in diseased intestines than healthy intestines, and the richness of bacteria could not fully indicate health status [65]. The representative microbes that could reflect the balance of microbial communities and contribute to intestinal health should be considered, and they might also vary in different species or life stages.

For the turtles in this study, the dominant phyla were Proteobacteria, Bacteroidetes, Firmicutes and Fusobacteria in different habitats, which were similar to the taxa in freshwater fish such as crucian carp, grass carp, and bighead carp (Hypophthalmichthys nobilis) [66] and marine turtles such as green turtles (Chelonia mydas) [28]. Previous studies indicated that there was a clear difference in composition between aquaculture-reared and wild aquatic animals: in the wild species, Proteobacteria was always the most abundant phylum, whereas Firmicutes was the most abundant phylum in the aquaculture-reared species $[67,68]$. For the turtles in this study, it was also found that Firmicutes was the most abundant phylum in the guts of turtles sampled from the greenhouse under the initial intensive aquacultural conditions, whereas Proteobacteria was the most abundant phylum after cultivation in ponds, lakes and paddy fields, especially at $120 \mathrm{~d}$. The results also indicated that the gut microbiota of turtles had both intrinsic and distinct environmental characteristics. Aeromonas, Chryseobacterium and Citrobacter commonly exist in European pond turtles kept in breeding centers, and there were obvious differences in bacterial composition and abundance for turtles of different ages [69]. The composition and abundance of gut bacteria also varied with different physical statuses, and the virulence and prevalence of pathogens were suppressed in healthy individuals [70]. Cetobacterium, Cyanobacterium and Clostridiaceae were more abundant in healthy fish, whereas Aeromonas, Vibrio and Shewanella OTUs were more abundant in diseased individuals [71]. Enterococcus spp. and Citrobacter spp. were the dominant bacteria in healthy turtles, while Citrobacter spp., Aeromonas spp. and Bacillus spp. were predominant in diseased turtles [72]. Lactococcus garvieae, Citrobacter freundii and Edwardsiella tarda were commonly pathogenic bacteria in aquatic environments [73]. In this study, Edwardsiella spp. was occasionally found in samples from ponds but rarely 
found in those from paddy fields and lakes. Aeromonas spp. and Citrobacter spp. were absent in almost all samples. Bacillus spp. were more abundant in paddy fields than in lakes and ponds at $60 \mathrm{~d}$. Pseudomonas spp. existed widely and were rich in most samples except hindgut samples from pond turtles at $60 \mathrm{~d}$. In addition, the nonpathogenic bacteria Enterococcus faecium, Enterococcus hirae, Haemophilus segnis, Ochrobactrum anthropi and Pseudomonas spp. could also induce carapace and plastron damage when the cultural environment became poor. The relationship between gut microbial communities and bodily health was not static, and the gut microbial community was mutually adapted to the internal and external environments. Therefore, the relationship among microbial communities in the gut, culture water and soil should also be detected to reveal the adaptation of turtles to different habitats.

It is necessary to optimize feeding regimes and cultural conditions to improve the economic and environmental sustainability of aquaculture. Burgeoning culture modes in reconstructive outdoor ponds and paddy fields have been developed to replace hothouse cultivation, especially in the later life stages before coming into the market. In this study, the turtles cultured in paddy fields presented the maximum growth rate. The rice production was relative stable or increased under a low area of furrow or ponds in field paddy ( $\leq 10 \%$ of the total planting area) and the mutual promotion of rice and aquatic animals. Moreover, coculture could increase the value of rice and turtles with a marked decrease in fertilizer and pesticide utilization. The rice-turtle coculture modes were widely developed and were suitable in both single and double cropping rice cultivation area. All of these results indicated that the coculture mode was economic and ecological. The coculture mode could be optimized by reasonable soil, water and fertilizer management, especially nitrogen fertilization and creating a feeding regime of turtles on the basis of digestibility, which could minimize nutrient outputs and decrease the environmental impacts of intensive culture [74, 75]. Rice-turtle coculture is an economic and ecological integrated culture mode that might play important roles in paddy field environmental protection and food security due to the sharp decrease in the utilization of chemical fertilizers and pesticides with this method compared to that under traditional planting modes. The mutual promotion of the field environment and turtle health were preliminarily detected in the present study, but the effectiveness and potential of this method should be investigated more systematically in future work.

\section{Conclusions}

The juvenile Chinese soft-shelled turtles could adapt to different habitats, including natural lakes, artificial ponds and paddy fields. The divergence in growth, appearance, physiological characteristics and gut microbial communities was observed within a relatively short term. The species of microbes were significantly more diverse in paddy field specimens than in those from ponds and lakes. The diversity and abundance of gut microbes were also higher for turtles from paddy fields than for those from lakes and ponds. Significant divergence was found in summer, whereas relatively less diversity was detected in late autumn. The abundances of dominant phyla and genera were obviously different in various habitats at specific sampling times. Sampling time and habitat had significant effects on turtle metabolism, especially amino acid and carbohydrate metabolism. Rice-turtle coculture is a potential ecological and economic farming mode that plays important roles in wild turtle protection, food security and paddy field environment improvement.

\section{Methods}

\section{Experimental habitats and turtle rearing}

The turtles (Pelodiscus sinensis, Japanese strain) were intensively bred in a standardized aquafarm of Xijiang Aquaculture Co., Ltd., located in Anqing, China. The turtles were stocked in cement tanks in hothouses with relatively stable conditions (temperature was $30.0 \pm 1.0^{\circ} \mathrm{C}$ and water depth was approximately $0.5 \mathrm{~m}$ ) before being allocated to different experimental habitats. The turtles were fed to apparent satiation once a day with commercial feed containing $46 \%$ crude protein (Haihuang, Hangzhou, China). Thereafter, thousands of juvenile turtles of a similar size of approximately $340 \mathrm{~g}$ were purchased and randomly divided into three groups that were allocated to different experimental culture habitats as follows. Natural Lake (L): Bohu Lake is located in Anqing, Anhui Province, China (E116 $\left.22^{\prime}, \mathrm{N} 30^{\circ} 13^{\prime}\right)$ and belongs to the Yangtze River basin. It covers $217 \mathrm{~km}^{2}$, and the average water depth is approximately $3.5 \mathrm{~m}$ from July to October. The lake is abundant in fish, shellfish and other aquatic species. Two thousand marked turtles were released to the lake, and no artificial feeds were provided. The artificial release was conducive to the recovery of the wild turtle population. Artificial Pond (P): The quadratic artificial ponds equipped with feeding and basking facilities were located in the above mentioned standard aquafarm $\left(116^{\circ} 54^{\prime} \mathrm{E}\right.$, $30^{\circ} 28^{\prime} \mathrm{N}$ ). The experimental ponds were approximately $2000 \mathrm{~m}^{2}$ and $1.5 \mathrm{~m}$ deep. One thousand turtles were allocated to the pond. The turtles were fed commercial feed that contained $43 \%$ crude protein (Haihuang, Hangzhou, China) twice daily at 09:00 AM and 16:00 PM, and the daily feeding ration was $4 \%$ during the experiment. Paddy Field (F): The experimental paddy fields (E116 $21^{\prime}$, $\mathrm{N} 30^{\circ} 18^{\prime}$ ) were approximately $2000 \mathrm{~m}^{2}$ and surrounded by facilities to prevent escape. The area was modified for turtle cultivation with a $200 \mathrm{~m}^{2}$ pond (1.5 m deep), which was approximately $10 \%$ of the total field area. Two 
hundred turtles were allocated to each paddy field. The turtles were fed commercial feed twice a day like those in ponds, but the feeding ration was $3 \%$. The rearing experiment was conducted for 120 days from July to November. Air temperature was monitored at 11:00 AM every day during the experiment, which varied in the range of $22.5{ }^{\circ} \mathrm{C} \sim 35.8{ }^{\circ} \mathrm{C}$. Water temperature, $\mathrm{pH}$ and dissolved oxygen were monitored daily with a multiparameter water quality analyzer (YSI ProPlus, Yellow Springs, Oh, USA). In addition, ammonium nitrogen and nitrite nitrogen were measured weekly. During the experiment, the water temperature was $21.8{ }^{\circ} \mathrm{C} \sim 33.6{ }^{\circ} \mathrm{C}$, pH $7.8 \sim 8.2$, DO > $5.0 \mathrm{mg} / \mathrm{L}$, ammonium nitrogen $<0.5 \mathrm{mg} / \mathrm{L}$, and nitrite nitrogen $<0.2 \mathrm{mg} / \mathrm{L}$. Partial water changes were performed when the water quality became poor in the ponds and the small ponds in paddy fields. The change interval was approximately 20 days in summer and 30 days in autumn.

\section{Measurement and sampling}

Turtles were randomly collected at $0 \mathrm{~d}$ and $60 \mathrm{~d}$, and then as many as possible were collected at $120 \mathrm{~d}$ for measurement. The turtles collected from different habitats were randomly numbered, the investigator who selected individuals for analysis was unaware of the grouping details, and another investigator (also unaware of grouping details) conducted the anesthetic and anatomical procedures. Every three male individuals with no trauma, bruises or scars from each habitat and cultural periods were collected for sampling. The turtles were anesthetized and euthanized during measuring and sampling. The turtles were anesthetized after $48 \mathrm{~h}$ of fasting by intramuscular injection with tiletamine and zolazepam (1:1) at a dosage of $30 \mathrm{mg} / \mathrm{kg}$. The turtles were under deep anesthesia and unconscious within 15-20 min after injection from the left foreleg. The somatotype index, including body weight, carapace length, carapace width and calipash lateral width, was measured. Then, turtles were quickly decapitated in an unconscious state and dissected by sharp bone shears. The livers, clumpy fat, and guts were carefully removed on ice and weighed under sterile conditions. Gut length, i.e., the length from the end of the esophagus to the end of the rectum were separated and made straight and then measured without tensile force by using an electronic Vernier caliper (Guanglu. Guilin, China). The gastrointestinal tract of turtle is structurally complex and the morphology, digestive function are different in different intestine parts. In consideration of the potential differences on morphology, digestive function and microbial communities for different gut sections, we chose both foregut and hindgut as objects to compare the differences on microbial composition and dynamic variation in different habitats and sampling time. The gastric area (expressed as foregut " $\mathrm{F}$ ") and rectum (expressed as hindgut "L") were separated, rapidly frozen in liquid nitrogen, and then stored at $-80{ }^{\circ} \mathrm{C}$ until DNA extraction for microbial analysis. The grouping details are listed in Table 2 . The specific growth rate (SGR), hepato-somatic index (HSI), fat-somatic index (FSI), and gut-somatic index of weight $\left(\mathrm{DSI}_{\mathrm{W}}\right)$ and length $\left(\mathrm{DSI}_{\mathrm{L}}\right)$ were calculated. All operations on turtles were conducted in accordance with the institutional animal care guidelines and the supervision of Anhui Academy of Agricultural Sciences committees.

\section{Bacterial DNA extraction and 16 S rRNA gene amplicon sequencing}

Bacterial DNA extraction was conducted using a TIANamp Stool DNA Kit (DP328, TIANGEN, Beijing, China) according to the manufacturer's instructions. The V4 V5 variable region of the $16 \mathrm{~S}$ rRNA gene was amplified by the bacterial primers $515 \mathrm{~F}$ (5'-GTGCCA GCMGC CGCGGTAA-3') and 907R (5'-CCGTCAAT TCMTTTRAGT TT-3') with overhang adapters attached. The PCRs $(25 \mu \mathrm{L})$ contained approximately 2.5 $\mu \mathrm{L}$ DNA templates $(5 \mathrm{ng} / \mu \mathrm{L}), 5.0 \mu \mathrm{L}$ reverse/forward primer $(1 \mu \mathrm{M})$, and $12.5 \mu \mathrm{L} 2 \times \mathrm{KAPA} \mathrm{HiFi}$ HotStart Ready Mix. PCR was performed on a Step One Plus Real-time PCR System (Thermo Fisher Scientific, Waltham, MA, USA) with the following program: $95{ }^{\circ} \mathrm{C}$ for $3 \mathrm{~min}$, followed by 25 cycles of $30 \mathrm{~s}$ at $95{ }^{\circ} \mathrm{C}, 30 \mathrm{~s}$ at $55{ }^{\circ} \mathrm{C}$, and $30 \mathrm{~s}$ at $72{ }^{\circ} \mathrm{C}$ with a postamplification extension of $10 \mathrm{~min}$ at $72{ }^{\circ} \mathrm{C}$. The products were confirmed by agarose gel electrophoresis (Peiqing, Shanghai, China). AMPure $\mathrm{XP}$ beads (Beckman Coulter, Indianapolis, IN, USA) and fresh $80 \% \mathrm{EtOH}$ were used to purify the $16 \mathrm{~S} \mathrm{~V} 4$ and V5 amplicons away from free primers and primer dimer species for index PCR. Dual indices and Illumina sequencing adapters were attached by using the Nextera XT Index Kit (FC-131-1002, Illumina, San Diego, CA, USA). PCR was performed on a thermal cycler using the following program: $95{ }^{\circ} \mathrm{C}$ for $3 \mathrm{~min}$, followed by 8 cycles of $30 \mathrm{~s}$ at $95^{\circ} \mathrm{C}, 30 \mathrm{~s}$ at $55{ }^{\circ} \mathrm{C}$, and $30 \mathrm{~s}$ at $72{ }^{\circ} \mathrm{C}$ with a postamplification extension of $5 \mathrm{~min}$ at $72{ }^{\circ} \mathrm{C}$. AMPure XP beads were used to clean up the final library before quantification, normalization and pooling. The purified bacterial DNA samples were sent to Sangon Biotech Co., Ltd. (Shanghai, China) for Illumina MiSeq sequencing.

\section{$16 \mathrm{~S}$ Metagenomics sequencing analysis}

The sequencing analysis methods were mainly as described by Campos et al. (2018) and Abdelrhman et al. (2016) $[28,76]$. The obtained DNA reads were compiled in FastQC version 0.11 .5 for further processing. QIIME version 1.9.1 was used for microbiome analysis of raw DNA sequencing data, including demultiplexing and quality filtering, OTU picking, taxonomic assignment, phylogenetic reconstruction, diversity analyses and visualizations. The barcode and primer sequences were cut off after the samples were loaded, read pairs were 
merged using PANDAseq assembler version 2.10 for raw tags, and the sequences were filtered if there was no overlap between them. Then, the chimeras and host sequences were further filtered for clean tags. Singletons were removed before operational taxonomical unit (OTU) clustering (with an identity threshold of $97 \%$ ). The valid data were clustered into OTUs using UPARSE. The rarefaction curves for each sample were produced, and diversity values were estimated on rarefied OTUs [77]. The distances among samples were calculated according to the abundance, and the samples were clustered on OTUs to evaluate the similarity. The cluster dendrogram and a phylogenetic tree were also built. Specific differences in community composition were determined using PCoA based on the Bray-Curtis distance matrix. OTUs were taxonomically classified using USEARCH (a unique sequence analysis tool) version 5.2.236 against GreenGenes databases and compiled into each taxonomic level. The composition, abundance and diversity analyses of OTUs were conducted for the species richness and evenness and mutual or proper traits of OTUs for various samples or groups. A test of the significance of differences in OTU composition was conducted using LEfSe analysis to identify the various species. The prediction of microbial community function was conducted by using PICRUSt to evaluate the abundance of functional genes in the samples [78].

\section{Statistical analysis}

All differences among biometric measurements were determined by analysis of variance (ANOVA) using SPSS 20.0. The measured data were subjected to one-way ANOVA. Differences among treatments were tested by Tukey's multiple range test, and $p<0.05$ indicated statistically significant differences. Duncan's multiple comparison was carried out to determine the difference among repeated groups. All statistics on gut microbiota were conducted by using $\mathrm{R}$ (version 3.2.2).

Dr. Benli Wu, Long Huang, Jing Chen and Ye Zhang are research assistants at Fisheries Research Institute, Anhui Academy of Agricultural Sciences, and the research directions involve aquatic animal nutrition and environment, aquatic ecology and aquaculture.

Dr. Jun Wang is a lecturer at State Key Laboratory of Eco-hydraulic in Northwest Arid Region of China, and the research directions were fish ecology and aquatic resource protection.

\section{Abbreviations}

16S rRNA: 165 ribosomal RNA; OTU: Operational taxonomic unit; PCA: Principal component analysis; ANOVA: Analysis of variance; LEfSe: Linear discriminant analysis coupled with effect size; LDA: Liner discriminant analysis; PICRUSt: Phylogenetic Investigation of Communities by Reconstruction of Unobserved States

\section{Supplementary information}

The online version contains supplementary material available at https://doi. org/10.1186/s12866-021-02209-y.

Additional file 1: Fig. S1. The cluster dendrogram and phylogenetic tree for samples on OTUs, the grouping details were listed in Table 2.

Additional file 2: Fig. S2. The PCOA (principal co-ordinates analysis) on Bray-Curtis including initial samples from greenhouse, the different symbols represented different groups from different habitats and cultural periods, the grouping details were listed in Table 2.

Additional file 3: Fig. S3. The mutual and specific gut microbial species for groups from fields and ponds at 120d, the grouping details were listed in Table 2.

Additional file 4: Fig. S4. The predicted functional categories and pathway in KEGG level 2, the group details were listed in Table 2.

Additional file 5: Table S1. Number of observed total and dominant ('0.1\%) OTUs and counts in groups, the group details were listed in Table 2.

Additional file 6: Table S2. The nearest sequenced taxon index (NSTI) for groups from different habitats on OTUs,the group details were listed in Table 2.

\section{Acknowledgements}

We sincerely thank Xiang Wang and Song Wu for their assistance in sampling and environmental factors collection.

\section{Authors' contributions}

JXH and BLW conceptualized and designed the work, BLW drafted the manuscript, LH collected samples and performed the study, JC and YZ acquired important physiological and environmental data, JXH, LH and JW revised the manuscript and provided effective suggestions on data analysis. All authors read and approved the final manuscript.

\section{Authors' information}

Corresponding author Prof. Jixiang He is the deputy director of Fisheries Research Institute, Anhui Academy of Agricultural Sciences, and the major research directions are healthy aquaculture and nutrientphysiologyof aquaticanimals.

Dr. Benli Wu, Long Huang, Jing Chen and Ye Zhang are research assistants at Fisheries Research Institute, Anhui Academy of Agricultural Sciences, and the research directions involve aquatic animal nutrition and environment, aquatic ecology and aquaculture.

Dr. Jun Wang is a lecturer at State Key Laboratory of Eco-hydraulic in Northwest Arid Region of China, and the research directions were fish ecology and aquatic resource protection.

\section{Funding}

This work was supported by National Key Research and Development Project of China [2018YFD0300904-4], Key Research and Development Projects in Anhui Province [1704g07020118] and National Natural Science Foundation of China [51709225]. The funding agencies had no role in the study design, samples and data collection, analysis, and manuscript preparation.

\section{Availability of data and materials}

All data generated or analyzed during this study are included in this published article [and its supplementary information files]. Raw sequence data on 16s RNA gene had been submitted to the NCBI Sequence Read Archive (SRA) with the accession number PRJNA639398 (http://trace.ncbi.n/m.nih.gov/Traces/sra/).

\section{Declarations}

\section{Ethics approval and consent to participate}

The experimental protocol was established, according to the ethical guidelines of the Basel Declaration and was approved by the Experimental Animal Welfare and Ethical of Anhui Academy of Agricultural Sciences (NO.AAAS 2020-11). 


\section{Consent for publication}

Not applicable.

\section{Competing interests}

The authors declare that they have no competing interests.

\section{Author details}

'Key Laboratory of Aquaculture \& Stock Enhancement of Anhui Province, Fisheries Research Institute, Anhui Academy of Agricultural Sciences, No.40 Nongkenan Road, Luyang District, Hefei 230031, Anhui Province, China. ${ }^{2}$ State Key Laboratory of Eco-hydraulic in Northwest Arid Region of China, Xi'an University of Technology, 710048 Xi'an, China.

Received: 7 August 2020 Accepted: 29 April 2021

\section{Published online: 11 May 2021}

\section{References}

1. Nagai N, Kobayashi $H$, Katayama S, et al. Preparation and characterization of collagen from soft-shelled turtle (Pelodiscus Sinensis) skin for biomaterial applications. J Biomater Sci Polym Ed. 2009;20:567-76.

2. Lu JF, Wan Q, Yin ZM, et al. Extraction and characterization of collagen from calipash of Chinese soft-shelled turtle (Pelodiscus sinensis). Journal of Fisheries of China. 2010;34:801-8. (in Chinese with English Abstract).

3. Rhodin AGJ, Iverson R, Bour U, Fritz A, Georges HB, Shaffer PPV, Dijk JB. Turtles of the world annotated checklist and atlas of taxonomy, synonymy, distribution, and conservation status. 8th ed.: Baltimore:Johns Hopkins University Press; 2017.

4. Zhang J, Wang F, Jiang YL, et al. Modern greenhouse culture of juvenile soft-shelled turtle, Pelodiscus sinensis. Aquacul Int. 2017;25:1607-24.

5. Weng LP, Chen FD, Wang HH, et al. Investigation on the volatile flavor compounds of Pelodiscus sinensis grown in greenhouse by SPME-GC-MS. Food Industry. 2014;35:266-9. (in Chinese with English Abstract).

6. Chen X, Niu C, Pu L. Effects of stocking density on growth and non-specific immune responses in juvenile soft-shelled turtle, Pelodiscus sinensis. Aquacul Res. 2007;38:1380-6.

7. Zhou XQ, Niu CJ, Sun RY. The effects of vitamin E on non-specific immune response of the juvenile soft-shelled turtle Pelodiscus sinensis. Fisheries Sci. 2010;71:612-7.

8. Zhou XQ, Niu CJ, Sun RY. The effect of vitamin C on stress withstanding capability in the juvenile soft-shelled turtle (Pelodiscus sinensis). Aquacul Nutr. 2015:11:169-74.

9. Montalban-Arques A, Schryver PD, Bossier P, et al. Selective manipulation of the gut microbiota improves immune status in vertebrates. Front Immuno. 2015;6:512.

10. Standen B, Rodiles A, Peggs D, et al. Modulation of the intestinal microbiota and morphology of tilapia, Oreochromis niloticus, following the application of a multi-species probiotic. Appl Microbiol Biot. 2015;99:8403-17.

11. Cabello FC. Heavy use of prophylactic antibiotics in aquaculture: a growing problem for human and animal health and for the environment. Environ microbiol. 2006;8:1137-44.

12. Brandt KK, Amézquita A, Backhaus T, et al. Ecotoxicological assessment of antibiotics: A call for improved consideration of microorganisms. Environ Int. 2015:85:189-205

13. Patil HJ, Ayana BP, Alon $\mathrm{N}$, et al. Evidence of increased antibiotic resistance in phylogenetically-diverse aeromonas isolates from semi-intensive fish ponds treated with antibiotics. Front Microbiol. 2016;7:1875

14. Adel M, Yeganeh S, Dawood MAO, et al. Effects of Pediococcus pentosaceus supplementation on growth performance, intestinal microflora and disease resistance of white shrimp, Litopenaeus vannamei. Aquacult Nutr. 2017;23: 1401-9.

15. Chua MC, Benamor K, Lay C, et al. Effect of synbiotic on the gut microbiota of caesarean delivered infants: a randomized, double-blind, multicenter study. J Pediatr Gastr Nutr. 2017;65:102-6.

16. De Bruijn I, Liu Y, Wiegertjes GF, et al. Exploring fish microbial communities to mitigate emerging diseases in aquaculture. FEMS Microbiol Ecol. 2018;94: fix 161.

17. Guerreiro I, Serra CR, Pousão-Ferreira P, et al. Prebiotics effect on growth performance, hepatic intermediary metabolism, gut microbiota and digestive enzymes of white sea bream (Diplodus sargus). Aquacul Nutr. 2018;24:153-63.
18. He JX, Chen J, Song GT, et al. Comparison of nutritional composition and quality between the paddy-cultured and pond-cultured Pelodiscus sinensis Japanese strain. Journal of Anhui Agricultural University. 2017;44:1005-9. (in Chinese with English Abstract).

19. Marques TM, Wall R, Ross RP, et al. Programming infant gut microbiota: influence of dietary and environmental factors. Curr Opin in Biotech. 2010; 21:149-56.

20. Vrieze A, Holleman F, Zoetendal EG, et al. The environment within: how gut microbiota may influence metabolism and body composition. Diabetologia. 2010:53:606-13.

21. Snijders AM, Langley SA, Kim YM, et al. Influence of early life exposure, host genetics and diet on the mouse gut microbiome and metabolome. Nat Microbiol. 2016:2:16221.

22. Xiong JB, Nie L, Chen J. Current understanding on the roles of gut microbiota in fish disease and immunity. Zool Res. 2019:40:70-6.

23. Frei M, Becker K. Integrated rice-fish culture: Coupled production saves resources. Nat Resour Forum. 2005;29:135-43.

24. Tsuruta T, Yamaguchi M, Abe Sl, et al. Effect of fish in rice-fish culture on the rice yield. Fisheries Sci. 2011;77:95-106.

25. Hu L, Zhang J, Tang JJ, et al. The productivity of traditional rice-fish coculture can be increased without increasing nitrogen loss to the environment. Agr Ecosys Enviro. 2013;177:28-34.

26. Ghanbari M, Kneifel W, Domig KJ. A new view of the fish gut microbiome: advances from next-generation sequencing. Aquaculture. 2015:448:464-75.

27. Sullam KE, Essinger SD, Lozupone CA, et al. Environmental and ecological factors that shape the gut bacterial communities of fish: a meta-analysis. Mol Ecol. 2012:21:3363-78.

28. Campos P, Guivernau M, Prenafeta-Boldú FX, et al. Fast acquisition of a polysaccharide fermenting gut microbiome by juvenile green turtles Chelonia mydas after settlement in coastal habitats. Microbiome. 2018;6:69.

29. Stecher B, Maier L, Hardt W-D. 'Blooming' in the gut: how dysbiosis might contribute to pathogen evolution. Nat Rev Microbiol. 2013;11:277-84.

30. Yan Q, Li J, Yu Y, et al. Environmental filtering decreases with fish development for the assembly of gut microbiota. Environ Microbiol. 2016; 18:4739-54.

31. Fazeli M, Hassanzadeh P, Alaei S. Cadmium chloride exhibits a profound toxic effect on bacterial microflora of the mice gastrointestinal tract. Hum Exp Toxicol. 2011;30:152-9.

32. Clarke SF, Murphy EF, O'Sullivan O, et al. Exercise and associated dietary extremes impact on gut microbial diversity. Gut. 2014;63:1913-20.

33. Lee SM, Wong WP, Hiong KC, et al. Nitrogen metabolism and excretion in the aquatic Chinese soft-shelled turtle, Pelodiscus sinensis, exposed to a progressive increase in ambient salinity. J Exp Zool Part A. 2010;305A:995-1009.

34. Zha $Y$, Eiler A, Johansson $F$, et al. Effects of predation stress and food ration on perch gut microbiota. Microbiome. 2018:6:28.

35. Kim SG, Han XY, Wei D, et al. Influence of $\mathrm{Cu}^{2+}$-loaded silicate on the growth performance and microflora of crucian carp Carassius auratus. Dis Aquat Organ. 2009;85:239-43.

36. Baldo $L$, Joan LR, Toomingklunderud $A$, et al. Gut microbiota dynamics during dietary shift in eastern African cichlid fishes. PLoS One. 2015;10:e0127462.

37. Cremona $F$, Järvalt $A$, Bhele $U$, et al. Relationships between fisheries, foodweb structure, and detrital pathway in a large shallow lake. Hydrobiologia. 2018;820:145-63.

38. Koomen R, Herrmann E. The effects of social context and food abundance on chimpanzee feeding competition. AM J of Primatol. 2018;80:e22734.

39. Wang CF, Wang JP, Cao CG. Effect of rice-duck farming ecosystem on zoobenthos biodiversity in paddy field. Chinese Journal of Eco-Agriculture. 2008;16:933-7. (in Chinese with English Abstract).

40. Bartrons M, Arranz I, Cañedo-Argüelles $M$, et al. Fish shift the feeding behaviour and trophic niche diversification of their prey in subarctic Lake Mývatn. Iceland Hydrobiologia. 2018;816:896-906.

41. Lei SJ. Effects of ration level and feeding frequency on digestibility in juvenile soft-shelled turtle, Pelodiscus sinensis. J Zhejiang Univ B. 2006;7:5805. (in Chinese with English Abstract).

42. Wu BL, Luo S, Wang JW. Effects of temperature and feeding frequency on ingestion and growth for rare minnow. Physiol Behav. 2015;140:197-202.

43. Serra CR, Júnior FM, Couto A, et al. Gut microbiota and gut morphology of gilthead sea bream (Sparus aurata) juveniles are not affected by chromic oxide as digestibility marker. Aquacul Res. 2018;49:1347-56. 
44. Lin WY, Huang CH. Fatty acid composition and lipid peroxidation of softshelled turtle, Pelodiscus sinensis, fed different dietary lipid source. Comp Biochem Phys C. 2007;144:327-33.

45. Li XH, Zhou L, Yu YH, et al. Composition of gut microbiota in the gibel carp (Carassius auratus gibelio) varies with host development. Microbl Ecol. 2017; 74:1-11.

46. Wu GD, Chen J, Hoffmann C, et al. Linking long-term dietary patterns with gut microbial enterotypes. Science. 2011;334:105-8.

47. Merrifield DL, Shaw BJ, Harper GM, et al. Ingestion of metal-nanoparticle contaminated food disrupts endogenous microbiota in zebrafish (Danio rerio). Environ Pollut. 2013;174:157-63.

48. Zhou Z, Ringø E, Olsen RE, et al. Dietary effects of soybean products on gut microbiota and immunity of aquatic animals: A review. Aquacul Nutr. 2018; 24:644-65.

49. Goodrich JK, Davenport ER, Beaumont $M$, et al. Genetic determinants of the gut microbiome in UK twins. Cell Host Microbe. 2016;19:731-43.

50. Rawls JF, Mahowald MA, Ley RE, et al. Reciprocal gut microbiota transplants from zebrafish and mice to germ-free recipients reveal host habitat selection. Cell. 2006;127:423-33.

51. Nelson TM, Rogers TL, Carlini AR, et al. Diet and phylogeny shape the gut microbiota of Antarctic seals: a comparison of wild and captive animals. Environ Microbiol. 2013;15:1132-45.

52. Smith CC, Snowberg LK, Gregory CJ, et al. Dietary input of microbes and host genetic variation shape among-population differences in stickleback gut microbiota. ISME J. 2015;9:2515-26.

53. Stagaman K, Burns AR, Guillemin K, et al. The role of adaptive immunity as an ecological filter on the gut microbiota in zebrafish. ISME J. 2017;11:1360-9.

54. Masuoka H, Shimada K, Kiyosueyasuda T, et al. Transition of the intestinal microbiota of dogs with age. Bioscience of Microbiota Food Health. 2017; 36:27-31.

55. Schmidt V, Amaral-Zettler L, Davidson J, et al. Influence of fishmeal-free diets on microbial communities in Atlantic salmon (Salmo salar) recirculation aquaculture systems. Appl Environ Microb. 2016:82:4470-81.

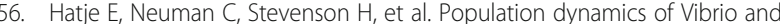
Pseudomonas species isolated from farmed tasmanian Atlantic salmon (Salmo salar L.): a seasonal study. Microb Ecol. 2014;68:679-87.

57. Zarkasi KZ, Taylor RS, Abell GC, et al. Atlantic salmon (Salmo salar L.) gastrointestinal microbial community dynamics in relation to digesta properties and diet. Microb Ecol. 2016;71:589-603.

58. Maurice CF, Cl Knowles S, Ladau J, et al. Marked seasonal variation in the wild mouse gut microbiota. ISME J. 2015;9:2423-34.

59. Patrick $S$, Willemsen $D$, Popkes $M$, et al. Regulation of life span by the gut microbiota in the short-lived African turquoise killifish. eLife. 2017;6:e27014

60. Zhang C. Interactions between gut microbiota, host genetics and diet relevant to development of metabolic syndromes in mice. ISME J. 2010;4: 232-41.

61. Kuz'mina W, Zolotareva GV, Sheptitskii VA. Effect of habitat conditions on proteinase and glycosidase activities in the gut microbiota of crucian carp in a wide range of pH. Russ J Ecol. 2014:45:303-9.

62. Wang $S$, Chen $L$, He M, et al. Different rearing conditions alter gut microbiota composition and host physiology in Shaoxing ducks. Sci Rep-UK 2018;8:7387

63. Turnbaugh PJ, Ley RE, Mahowald MA, et al. An obesity-associated gut microbiome with increased capacity for energy harvest. Nature. 2006;444: 1027-31.

64. Zhao LP. The gut microbiota and obesity: from correlation to causality. Nat Rev Microbio. 2013;11:639-47.

65. Tran NT, Zhang J, Xiong F, et al. Altered gut microbiota associated with intestinal disease in grass carp (Ctenopharyngodon idellus). World J Microbiol Biot. 2018;34:71.

66. Li XM, Yan QY, Xie SQ, et al. Gut microbiota contributes to the growth of fast-growing transgenic common carp (Cyprinus carpio L.). PLoS One. 2013;8: e64577

67. Ramírez C, Romero J. Fine flounder (Paralichthys adspersus) microbiome showed important differences between wild and reared specimens. Front Microbiol. 2017:8:271.

68. Wang AR, Ran C, Ring $\varnothing \mathrm{E}$, et al. Progress in fish gastrointestinal microbiota research. Rev Aquac. 2017;10:626-40.

69. Nowakiewicz A, Ziółkowska G, Zięba P, et al. Aerobic bacterial microbiota isolated from thecloaca of the European pond turtle (Emys orbicularis) in Poland. J Wildlife Dis. 2015;51:255-9.
70. Ahasan MS, Waltzek TB, Huerlimann R, et al. Comparative analysis of gut bacterial communities of green turtles (Chelonia mydas) pre-hospitalization and post-rehabilitation by high-throughput sequencing of bacterial $16 \mathrm{~S}$ rRNA gene. Microbiol Res. 2018;207:91-9.

71. Li T, Li H, Gatesoupe FJ, et al. Bacterial signatures of "Red Operculum" disease in the gut of crucian carp (Carassius auratus). Microb Ecol. 2017;74: $510-21$.

72. Zhu NY, Bei YJ, Zheng TL, et al. Comparison of bacteria floras in intestines of healthy and diseased Chinese soft-shelled turtles (Pelodiscus sinensis) and in aquatic water. Acta Agriculturae Zhejiangensis. 2014;26:1176-9. (in Chinese with English Abstract).

73. Barelli C, Albanese D, Donati C, et al. Habitat fragmentation is associated to gut microbiota diversity of an endangered primate: implications for conservation. Sci Rep-UK. 2015;5:14862.

74. Lee SM, Wong WP, Loong AM, et al. Postprandial increases in nitrogenous excretion and urea synthesis in the Chinese soft-shelled turtle, Pelodiscus sinensis. J Comp Physiol B. 2007;177:19-29.

75. Wang J, Qi Z, Yang Z. Evaluation of the protein requirement of juvenile Chinese soft-shelled turtle (Pelodiscus sinensis, Wiegmann) fed with practical diets. Aquaculture. 2014:433:252-5.

76. Abdelrhman KFA, Giovanni B, Cecilia M, et al. A first insight into the gut microbiota of the sea turtle Caretta caretta. Front Microbiol. 2016:7:1060.

77. He Y, Caporaso JG, Jiang XT, et al. Stability of operational taxonomic units: an important but neglected property for analyzing microbial diversity. Microbiome. 2015;3:20

78. Sun $\mathrm{BH}$. Wang $\mathrm{X}$, Bernstein $\mathrm{S}$, et al. Marked variation between winter and spring gut microbiota in free-ranging Tibetan Macaques (Macaca thibetana). Sci Rep-UK 2016; 6:26035.

\section{Publisher's Note}

Springer Nature remains neutral with regard to jurisdictional claims in published maps and institutional affiliations.

Ready to submit your research? Choose BMC and benefit from:

- fast, convenient online submission

- thorough peer review by experienced researchers in your field

- rapid publication on acceptance

- support for research data, including large and complex data types

- gold Open Access which fosters wider collaboration and increased citations

- maximum visibility for your research: over $100 \mathrm{M}$ website views per year

At $\mathrm{BMC}$, research is always in progress.

Learn more biomedcentral.com/submissions 